\title{
PKM PENDAMPINGAN PEMBUATAN ABON KULIT PISANG DI KABUPATEN TULUNGAGUNG
}

\author{
Siti Napfiah ${ }^{1}$, Asri Putri Anugraini ${ }^{2}$, Farizha Irmawati ${ }^{3}$ \\ ${ }^{1,2,3)}$ IKIP Budi Utomo, Malang, Jawa Timur, Indonesia \\ ${ }^{1 *}$ Email: napfiahsiti@gmail.com \\ ${ }^{2}$ Email: Asriputria8@gmail.com \\ ${ }^{3}$ Email: Farizha99@gmail.com
}

\begin{abstract}
Program society partnership is training abon's makings banana skin at Regency Tulungagung aims to give science and training makes a new innovation product namely abon banana skin in order to develop Regency citizen effort Tulungagung that not only utilize its banana only. At chooses two flaky producer partners bananas at Regency Tulungagung to been given training abon's makings that gets banana skin raw product. Two elected partner gets location at Kauman and Boyolangu. Two this effort partner not utilize its banana skin eventually well-nigh everyday making banana so banana skin flaky piles. By this program, given by science newing to that society banana skin can be utilized as a product that valuably namely abon banana skin. Reasonable banana skin to be made food product because banana skin have goodly nutrient content lovely. Abon reasonably to been kept up because top abon that than so long without bahna preservative and is liked by all society circle. Society devotion program this executed beginning month of February 2018. Via test-driving activity sort recipe and discussion with partner therefore at finds recipe to make abon banana skin who can get long-lasting, having a real treat, pretty color, and texture that nicely corresponds to banana skin type that is at partner effort place. Activity on programs it to get positive comment of Tulungagung's Regency citizen. They really enjoy to follow this activity.
\end{abstract}

Keyword: making, abon, banana skin, Tulungagung

\section{PENDAHULUAN}

Kabupaten Tulungagung merupakan salah satu kabupaten di Jawa Timur yangbelokasi di $154 \mathrm{~km}$ barat daya kota Surabaya (Ibu kota Provinsi Jawa Timur). Di daerah ini banyak ditemui tanaman pisang dan hal inimenjadikan warga memanfaatkannya untuk berwirausaha membuat keripik pisang. Seperti yang dilakukan oleh Ibu Wontinah yang berlokasi Kecamatan Kauman dan rumah Ibu Siti Mahmudah di Kecamatan Boyolangu. Kedua usaha ini setiap hari memproduksi keripik pisang yang mana hanya memanfaatkan buah pisangnya saja, sedangkan kulitnya menumpuk tidak dimanfaatkan untuk usaha.

Kedua usaha ini telah menjalankan usahanya sejak delapan tahun yang lalu. Jumlah karyawan yang dimiliki oleh masing- masing usahasekitar 20 orang. Kedua usaha ini ingin mengembangkan usahanya untuk meningkatkan pendapatan. Berdasarkan hal ini, tim pengabdian masyarakan memberikan tawaran solusi kepada kedua usaha untk mengembangkan usahanya dengan memanfaatkan kulit pisang untuk diolah menjadi abon. Abon memiliki keunggulan diantaranya disukai di bebagai kalangan dan dapat dimakan sebagai lauk maupun camilan.

\section{METODE PELAKSANAAN}

Program Kemitraan Masyarakat (PKM) ini dilaksanakan di dua usaha rumahan keripik pisang yakni di rumah Ibu Wontinah yang berlokasi di Desa Batangsaren Kecamatan Kauman sebagai mitra 1 dan rumah Ibu Siti Mahmudah di Desa Waung Kecamatan Boyolangu sebagai mitra 2. 
Kedua usaha ini berada di Kabupaten pengabdian dapat dilihat pada Gambar 1. Tulungagung. Diagram alir pelaksanaan

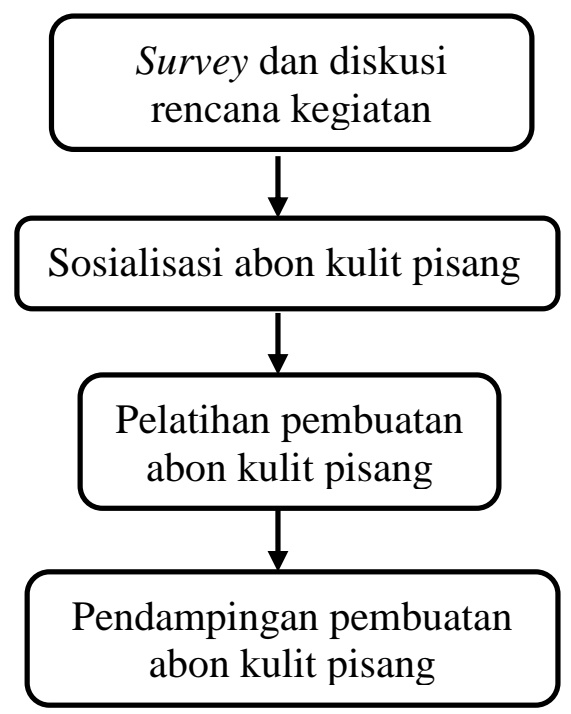

Gambar 1. Diagram Alir Pelaksanaan Pengabdian

Langkah pertama yang dilakukan adalah melakukan survey ke tempat usaha kedua mitra untuk mengetahui permasalahan dan merencanakan solusi untuk menghadapinya. Kemudian dilakukan diskusi rencana kerja untuk mencari solusi terhadap permasalahan yang ada. Solusi yang ditawarkan yaitu membuat produk baru yakni abon kulit pisang. Kegiatan survey dan diskusi ini dilaksanakn pada tanggal 28 Februari 2018. Langkah selanjutnya yaitu melaksanakn kegiatan sosialisai mengenai abon kulit pisang. Kegiatan sosialisasi dilaksanakan pada tanggal 1 April 2018 di rumah mitra 1 dan tanggal 2 April 2018 di rumah mitra 2.

Kemudian dilaksanakan kegiatan pelatihan pembuatan abon kulit pisang. Kegiatan pelatihan pembuatan abon kulit pisang dilaksanakan pada tanggal 21 April 2018 di rumah mitra 1 dan tanggal 22 April 2018 di rumah mitra 2. Dalam rangka untuk memantapkan proses produksi abon kulit pisang di kedua mitra, tim pengabdian melaksanakn kegiatan pendampingan pembuatan abon kulit pisang. Kegiatan pendampingan pembuatan abon kulit pisang dilaksanakan pada tanggal 27 Mei 2018 di rumah mitra 1 dan tanggal 28 Mei 2018 di rumah mitra 2.

\section{HASIL DAN PEMBAHASAN}

\section{A. Hasil Pengabdian Kepada Masyarakat}

Pelaksanaan pengabdian kepada masyarakat yang telah dilaksanakan yaitu sebagai berikut.

a. Survey dan Diskusi Rencana Kegiatan

\section{Surveydilaksanakan}

untuk mengetahui permasalahan dan merencanakan solusi untuk menghadapinya. Permasalahan pada kedua mitra produsen keripik pisang di Kabupaten Tulungagung ini hampir sama yaitu memiliki dua aspek permasalahan. Pertama, aspek masalah produksi yakni limbah kulit pisang yang menumpuk. Setiap hari memproduksi keripik buah pisang dimana yang dimanfaatkan adalah buahnya saja, sedangkan kulitnya tidak dimanfaatkan dalam usaha. Permasalahan kedua, aspek kehidupan ekonomi masyarakat yaitu warga ingin mengembangkan usahanya agar memperoleh keuntungan yang lebih tinggi.

Setelah survey, dilakukan diskusi rencana kerja untuk mencari solusi terhadap permasalahan yang ada. Solusi yang ditawarkan adalah membuat produk inovasi baru dengan memanfaatkan kulit pisang yang belum dimanfaatkan dalam usaha. Produk yang ditawarkan adalah produk abon karena abon memiliki keunggulan yaitu dapat 
bertahan lama dan disukai semua kalangan. Dengan keunggulan ini diharapkan poduk yang dibuat nanti dapat diterima di masyarakat global. Kedua mitra menyetujui solusi yang ditawarkan ini yaitu membuat abon kulit pisang. Berdasarkan diskusi maka disepakati bahwa akan diadakan kegiatan program kemitraan membuat abon kulit pisang. Diskusi rencana kerja ini dilaksanakan di rumah masing-masing mitra usaha. Kegiatan survey dapat dilihat pada Gambar 2. Diskusi rencana kegiatan PKM dengan mitra 1 dapat dilihat pada Gambar 3. Diskusi rencana kegiatan PKM dengan mitra 2 dapat dilihat pada Gambar 4.

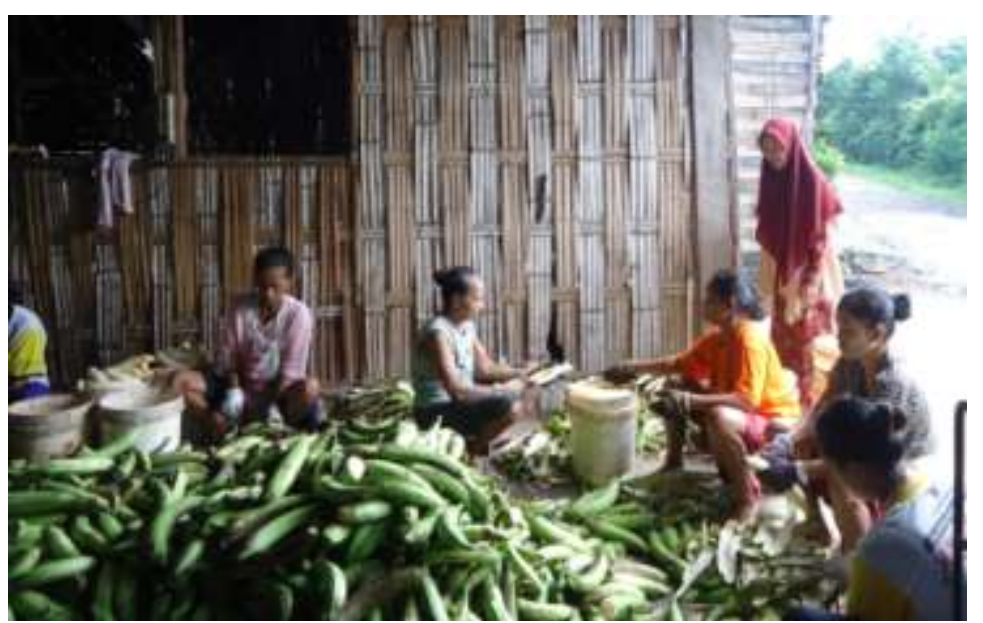

Gambar 2. Survey ke Lokasi Mitra (Sumber: doc. Pribadi, 2018)

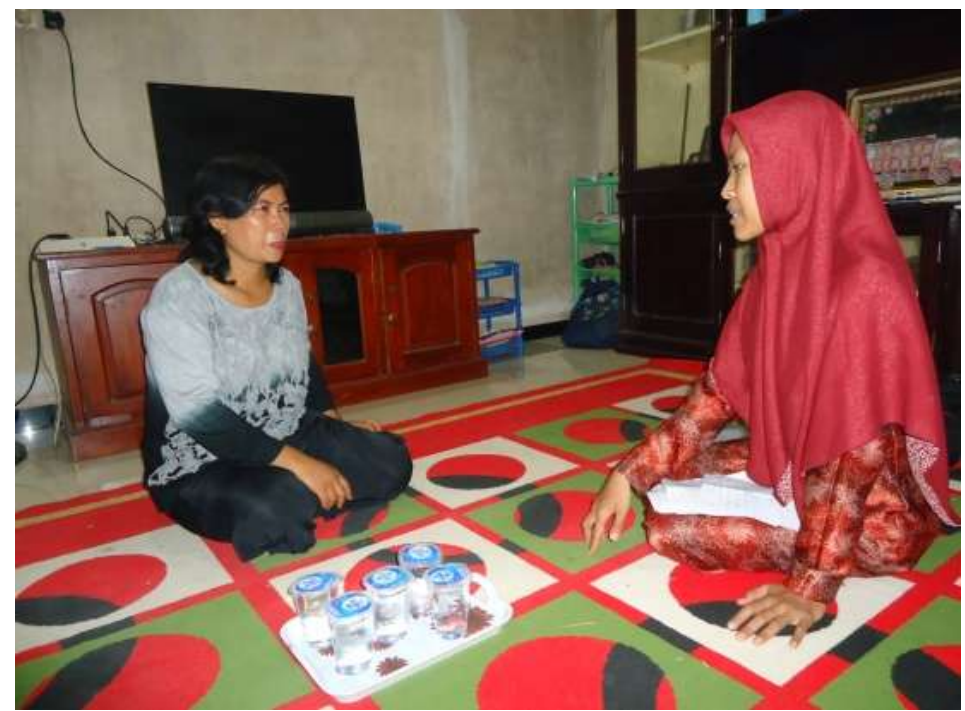

Gambar 3. Diskusi Rencana Kegiatan PKM di Mitra 1 


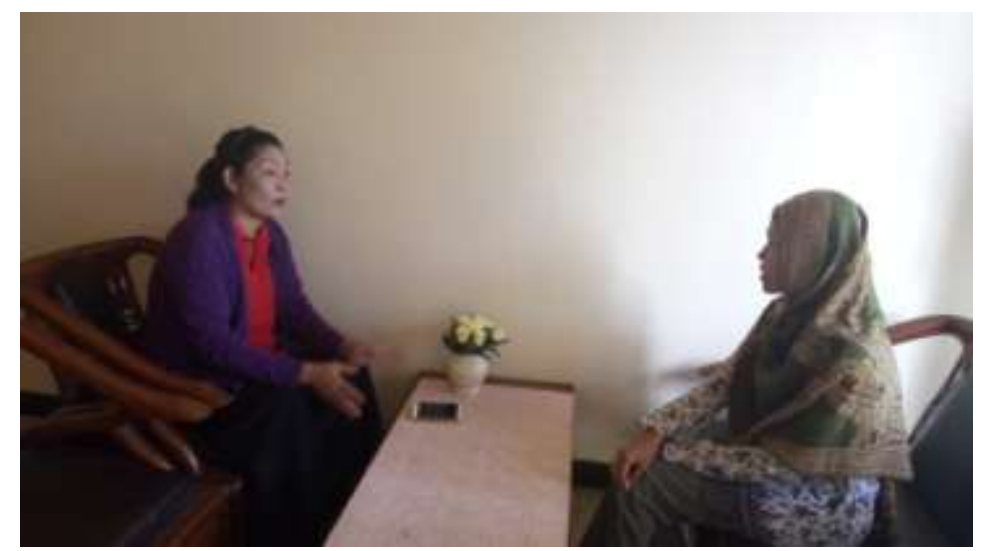

Gambar 4. Diskusi Rencana Kegiatan PKM di Mitra 2

b. Sosialisasi Abon Kulit Pisang

Kegiatan sosialisasi dilaksanakan untuk memberikan pengetahuan kepada masyarakat bahwa kulit pisang mempunyai kandungan gizi yang cukup bagus sehingga layak untuk dijadikan produk makanan abon. Jenis makanan abon layak untuk dipertahankan di Indonesia karena memiliki banyak keunggulan yakni disukai masyarakat luas di berbagai kalangan. Peserta yang hadir pada kegiatan sosialisasi yaitu karyawan di tempat usaha dan tetangga sekitar. Pada kegiatan ini juga dilakukan demonstrasi cara membuat abon kulit pisang. Peserta terlihat antusias memberikan tanggapan, mengajukan pertanyaan, atau memberikan saran dan idenya selama proses kegiatan. Kegiatan sosialisasi abon kulit pisang di lokasi mitra 1 dapat dilihat pada Gambar 5. Kegiatan sosialisasi abon kulit pisang di lokasi mitra 2 dapat dilihat pada Gambar 6.

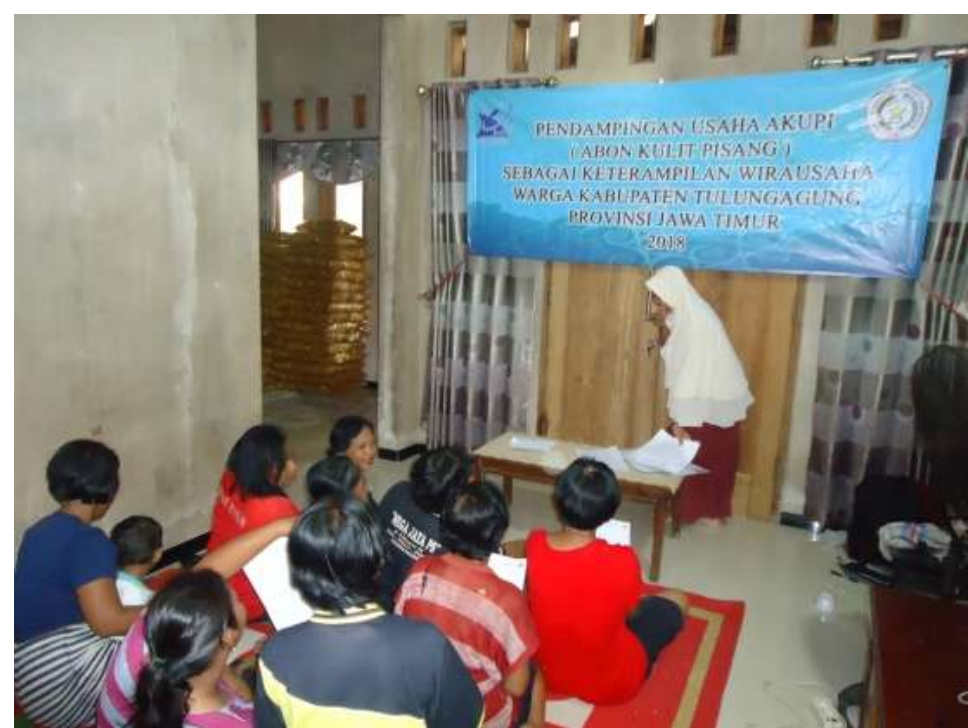

Gambar 5. Kegiatan Sosialisasi Abon Kulit Pisang di Lokasi Mitra 1 


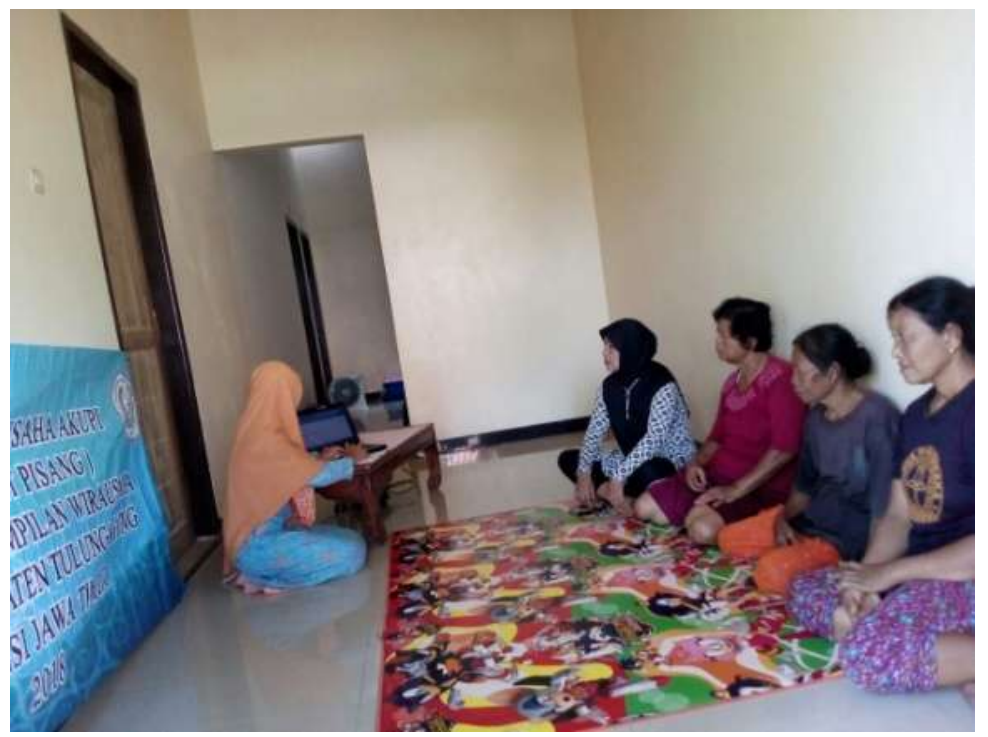

Gambar 6. Kegiatan Sosialisasi Abon Kulit Pisang di Lokasi Mitra 2

c. Pelatihan Pembuatan Abon Kulit Pisang

Kegiatan pelatihan pembuatan abon kulit pisang ini dilaksanakan di rumah masing-masing pemilik mitra usaha. Kegiatan ini dilaksanakan pada bulan April 2018. Pada saat pelatihan ini terbentuklah diskusi saling timbal balik untuk menghasilkan produk abon agar lebih baik. Kegiatan pelatihan pembuatan abon kulit pisang di mitra 1 dan mitra 2 dapat dilihat pada Gambar 7 dan Gambar 8.

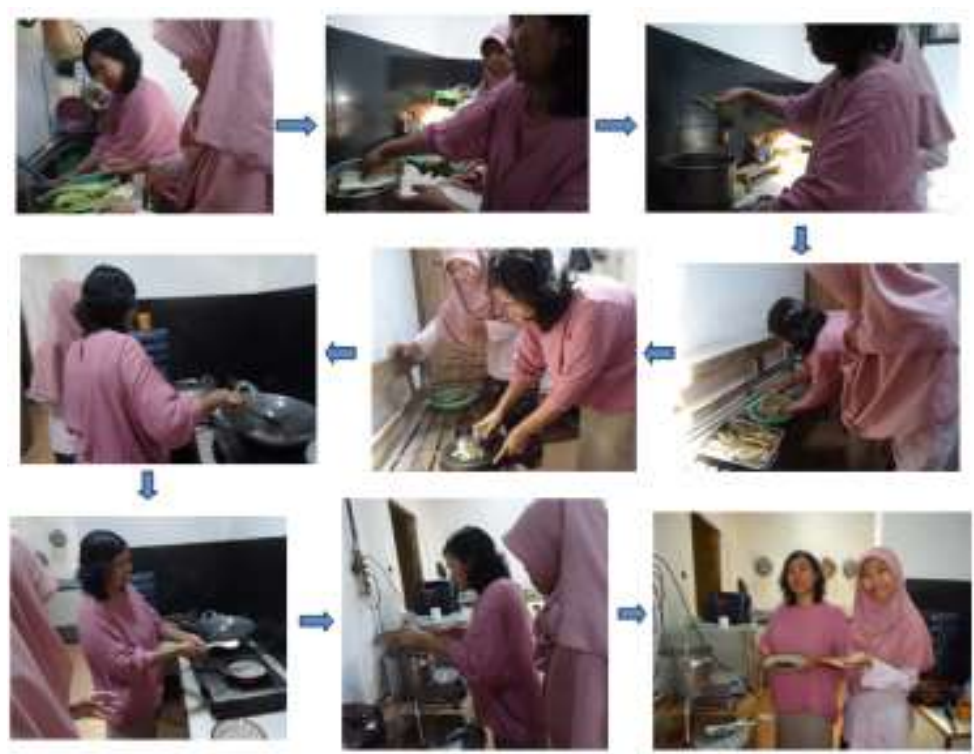

Gambar 7. Kegiatan Pelatihan Pembuatan Abon Kulit Pisang di Mitra 1 


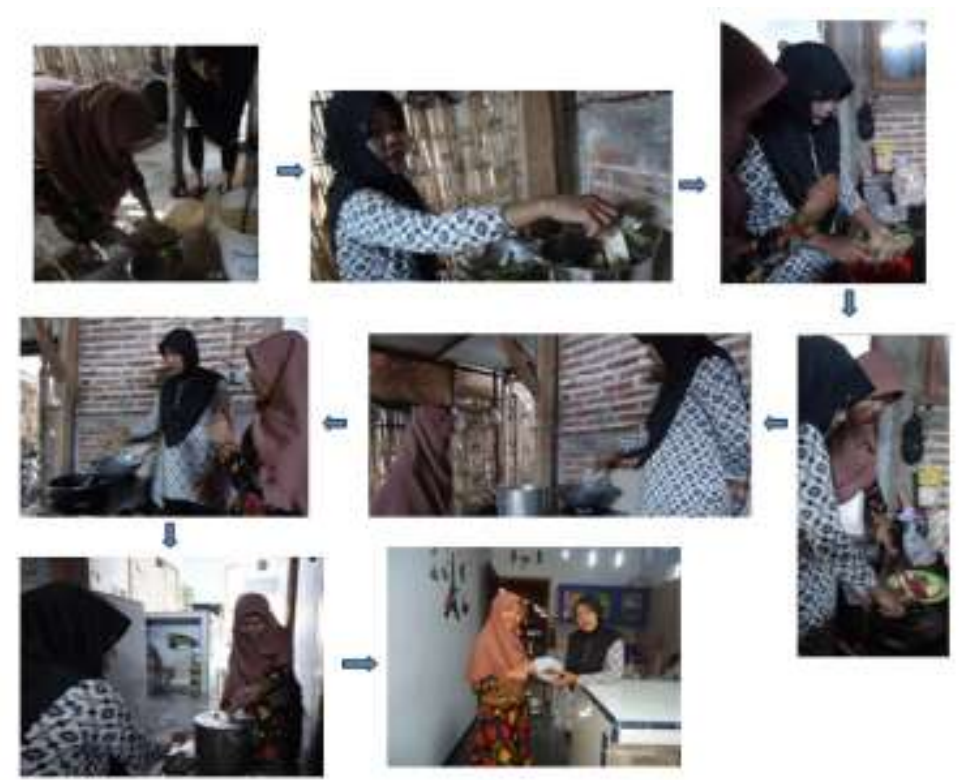

\section{Gambar 8. Kegiatan Pelatihan Pembuatan Abon Kulit Pisang di Mitra II}

d. Pendampingan Pembuatan Abon Kulit Pisang

Pendampingan pembuatan abon kulit pisang dilaksanakan pada bulan Mei 2018. Pendampingan dilakukan untuk memberikan arahan jika ada karyawan yang kurang tepat dalam proses produksi membuat abon.

\section{B. Pembahasan}

Hal yang paling penting adalah menemukan resep agar dapat menghasilkan produk yang tahan lama. Berdasarkan Pratiwi (2012) abon dapat bertahan lama jika proses pembuatannya tepat, diantaranya yaitu 1) proses menggoreng, gunakan minyak secukupnya agar hasil gorengan tidak terlalu berminyak dan masukkan abon ke penggorengan saat minyak sudah panas dengan cara sedikit demi sedikit agar tidak menggumpal; 2) penggunaan bumbu, tumis bumbu sampai benar-benar keing tapi jangan sampai gosong; 3) gunakan api sedang karena api besar akan menyebabkan gosong dan api kecil akan menyerap minyak banyak; 4) gunakan wadah bersih dan kering. Lama daya tahan abon dapat diketahui melalui proses penyimpanan di kemasan plastik yang higienis sampai ditemukan bau abon tengik.

Salah satu tahapan proses pembuatan kulit pisang ini yaitu mengukus kulit pisang. Seperti yang diungkapkan Rheza (2018) bahwa proses mengukus berguna untuk memudahkan proses menyuwir. Tahap akhir proses pembuatan abon kulit pisang ini dikemas yaitu meniriskan minyak menggunakan mesin spiner agar abon dapat bertahan lama. Seperti yang diungkapkan Farhanabdulh (2016) bahwa mesin peniris minyak dapat membuat abon menjadi tahan lama meskipun tana bahan pengawet, tekstur yang lembut, dan kering.

\section{KESIMPULAN}

Kesimpulan dari kegiatan pengabdian kepada masyarakat ini yaitu mitra usaha dapat mengembangkan usahanya dengan mengolah limbah kulit pisang menjadi produk abon ulit pisang. Sehingga limbah berkurang dan pendapatan meningkat.

\section{REFERENSI}

Farhanabdulh. 2016. Jual Mesin Spinner Abon Daging dan Ikan. https://mesina bonikansapi.wordpress.com

Pratiwi, Hesti. 2012. Agar Abon Buatan Sendiri Tahan Lama. https://nasional. kompas.com.

Rheza, Galih. 2018. Pengolahan Abon sebagai Salah Satu Inovasi Usaha untuk Meningkatkan Nilai Jual Daging. https://tokomesinovasi.com. 